\title{
Mid- to long-term results of modified non- vascularized allogeneic fibula grafting combined with core decompression and bone grafting for early femoral head necrosis
}

\author{
Chen Changjun ${ }^{\dagger}$, Li Donghai ${ }^{\dagger}$, Zhao Xin, Chen Liyile, Wang Qiuru and Kang Pengde*
}

\begin{abstract}
Purpose: The aim of this study was to determine mid-and-long term follow-up results of patients with early femoral head osteonecrosis who were treated by modified free vascularized fibular grafting combined with core decompression and bone grafting.

Methods: Forty-four patients at early ONFH were included in this study. Visual analog scale (VAS) pain scores, range of hip motion (ROM), and Harris hip score (HHS) were recorded to assess the clinical outcome; Western Ontario McMaster Osteoarthritis index (WOMAC) scores and Short Form 36 health survey (SF-36) were conducted to measure the living quality; $X$-ray film or magnetic resonance imaging (MRI) was used to evaluate radiographic progression; survivorship was defined as patients did not undergo the total hip arthroplasty (THA) or fusion at the last follow-up. Median follow-up was 7.4 years (6-8.2 years).

Results: The mean VAS score, ROM, and HHS were significantly improved at the final follow-up compared with preoperative values $(p<0.001)$. Health assessment including WOMAC scores and SF-36 were also better than those preoperatively $(p<0.001)$. Seven patients progressed to Ficat III and the four patients progressed to Ficat IV with osteoarthritis. Eight patients who cannot tolerate the pain and had poor living quality underwent THA.

Conclusion: Modified non-vascularized allogeneic fibula Grafting combined with core decompression and bone grafting could improve the clinical outcomes and enhance the quality of life for patients with early ONFH.
\end{abstract}

\section{Introduction}

Osteonecrosis of the femoral head (ONFH), characterized by reduced local blood flow, death of the osteocytes, and the bone marrow, is a frequently disease occurring in young individuals, which can lead to a progressive destruction of bone architecture, subchondral fracture, extensive hip pain, and loss of joint function [1]. And most of the patients usually progress to the collapse of the femoral head within a mean time of 2 years and even severe secondary symptomatic hip arthritis, as a result, they have

\footnotetext{
* Correspondence: kangpengde1969@163.com

${ }^{\dagger}$ Chen Changjun and Li Donghai contributed equally to this work.

Department of Orthopaedics, West China Hospital, Sichuan University, 37\# Guoxue Road, Chengdu 610041, People's Republic of China
}

to require total hip arthroplasty (THA) to restore joint function [2, 3] . Furthermore, THA is not the best option for young patients because prosthetic replacements rarely last for their lifetime and the associated complications might lead to revision surgery [4]. Thus, effective measures should be taken to treat ONFH as early as possible.

Until now, the optimal treatment for patients with symptomatic early-stage osteonecrosis of the femoral head is still controversial. Normally, conservative treatment and operation are the main methods that we can choose. And some comparatively non-operative methods, such as extracorporeal shock waves, have appeared to be effective in the short term, but the long-term effect is unknown [5]. Actually, most patients still have to refer to operation for

(c) The Author(s). 2020 Open Access This article is distributed under the terms of the Creative Commons Attribution 4.0 International License (http://creativecommons.org/licenses/by/4.0/), which permits unrestricted use, distribution, and reproduction in any medium, provided you give appropriate credit to the original author(s) and the source, provide a link to the Creative Commons license, and indicate if changes were made. The Creative Commons Public Domain Dedication waiver (http://creativecommons.org/publicdomain/zero/1.0/) applies to the data made available in this article, unless otherwise stated. 
further treatment, and operation methods are various, ranging from core decompression, fibular, or iliac bone grafting to Tantalum rod implantation [6-9]. Other methods to protect the femoral head including transtrochanteric rotational osteotomy, which is aimed to move the affected areas of the femoral head away from the main weight-bearing regions of the joint; however, the treatment effects were still controversy after studied for ages $[10,11]$. Furthermore, core decompression combined with tantalum rod placement or fibular grafting is also an effective measure to support the subchondral architecture with a comparatively good success rate, but little bone ingrowth and insufficient mechanical support of subchondral bone can still be seen in some cases [12,13]. On the other hand, though some disadvantages of vascularization bone grafting have been reported, such as increased measurable but acceptable complication and morbidity risk [14], vascularized fibular grafts was still advocated for most surgeons for vascularization of the graft could enhance its incorporation to the decompression channel, maintain graft viability, and provide perfusion the osteonecrotic area [15-17]. And it has been proved that free vascularized fibular grafting can improve vascularity compared with core decompression in the treatment of femoral head osteonecrosis, which is effective on pain-relieving and function recovering [9]. However, considering the complexity of free vascularized fibula graft, impracticality for community hospitals, and high costs of tantalum rod implantation, an effective and inexpensive method should be found for some less affluent population to delay the progression of ONFH and protect the femoral head before it collapses.

Promoting the repair of defects and improving mechanical support are two significant points. Core decompression with necrosis bone removed causes the bone defects and increases the risk of fracture for lacking the support structures to the subchondral bone area. Thus, in this study, we try to improve the blood supply, protect the mechanical property, and reduce the complexity of the procedures by using modified non-vascularized allogeneic fibula grafting combined with core decompression and bone grafting to treat early ONFH, and evaluate its clinical results, living quality, radiographic outcomes, and survivorship at mid- to long-term follow-up.

\section{Patients and methods}

The study was approved by the Clinical Trials and Biomedical Ethics Committee of West China Hospital, and written informed consent was obtained from all participants. According to the Ficat classification of ONFH, patients whose stage were at Ficat II of ONFH were included in our study. And patients whose previous drug therapy, disease, or surgery histories might influence the outcomes were excluded from the study. Between 2009 and 2011, 50 patients younger than 50 years of age with early ONFH were operated on using the authors' technique and 44 were available for review in the current study. The diagnosis of osteonecrosis of the femoral head was mainly plain radiographs and confirmed with magnetic resonance imaging. The patients' background and details are listed in Table 1.

\section{Surgical technique}

Before the surgery, non-vascularized allogeneic fibula was obtained from the bone bank of the hospital with the antigen removed by cryogenic freezing. Some holes were made around the fibula with a drill of $1 \mathrm{~mm}$ in diameter by the purpose of making it easier for the new bone tissue growing into the allogeneic fibula (Fig. 1).

All cases were performed by a single senior surgeon (PD Kang) using the same surgical technique: the decompression channel up to the subchondral bone and necrosis area was made by hollow trephine via the navigation of Kirschner wire under fluoroscopic control in the femoral head, which was used to drill a hole at area $6 \mathrm{~cm}$ below the femoral greater trochanter vertex and through the neck of the femur (Fig. 1). And then, removed the dead bone through the decompression channel with curet and sent for pathologic examination (Fig. 1). After that, the cancellous bone obtained from the area of the femoral trochanter through the decompression channel was compacted to the femoral head and then modified the form of the non-vascularized allogeneic fibula and grafted it to the channel. The fibula was knocked by a bone hammer to make it located tightly and the rest of autogenous cancellous bone was filled to the space around the grafted fibula. The distal end of the fibula should reach the area $5 \mathrm{~mm}$ below the surface of the femoral head. Fluoroscopy confirmed the adequacy of the positioning of the graft. After the procedure, conventional analgesic and thromboprophylaxis were conducted and functional exercise with active flexion and abduction of the surgery hip was performed. Walking with a crutch and light-touch weightbearing were advised before the third post-operative

Table 1 Demographic characteristic of the patients

\begin{tabular}{ll}
\hline Parameters & Median (range) \\
\hline Total number & 44 patients (44 hips) \\
Age (years) & $36.46(26-47)$ \\
Body mass index $\left(\mathrm{kg} / \mathrm{m}^{2}\right)$ & $23.8(18.8-27.6)$ \\
Gender (male/female) & $29 / 15$ \\
Etiology & \\
$\quad$ Alcohol-induced & 26 \\
$\quad$ Steroid-induced & 15 \\
$\quad$ Idiopathic & 3 \\
Classification & \\
$\quad$ Ficat II & 44 \\
\hline
\end{tabular}




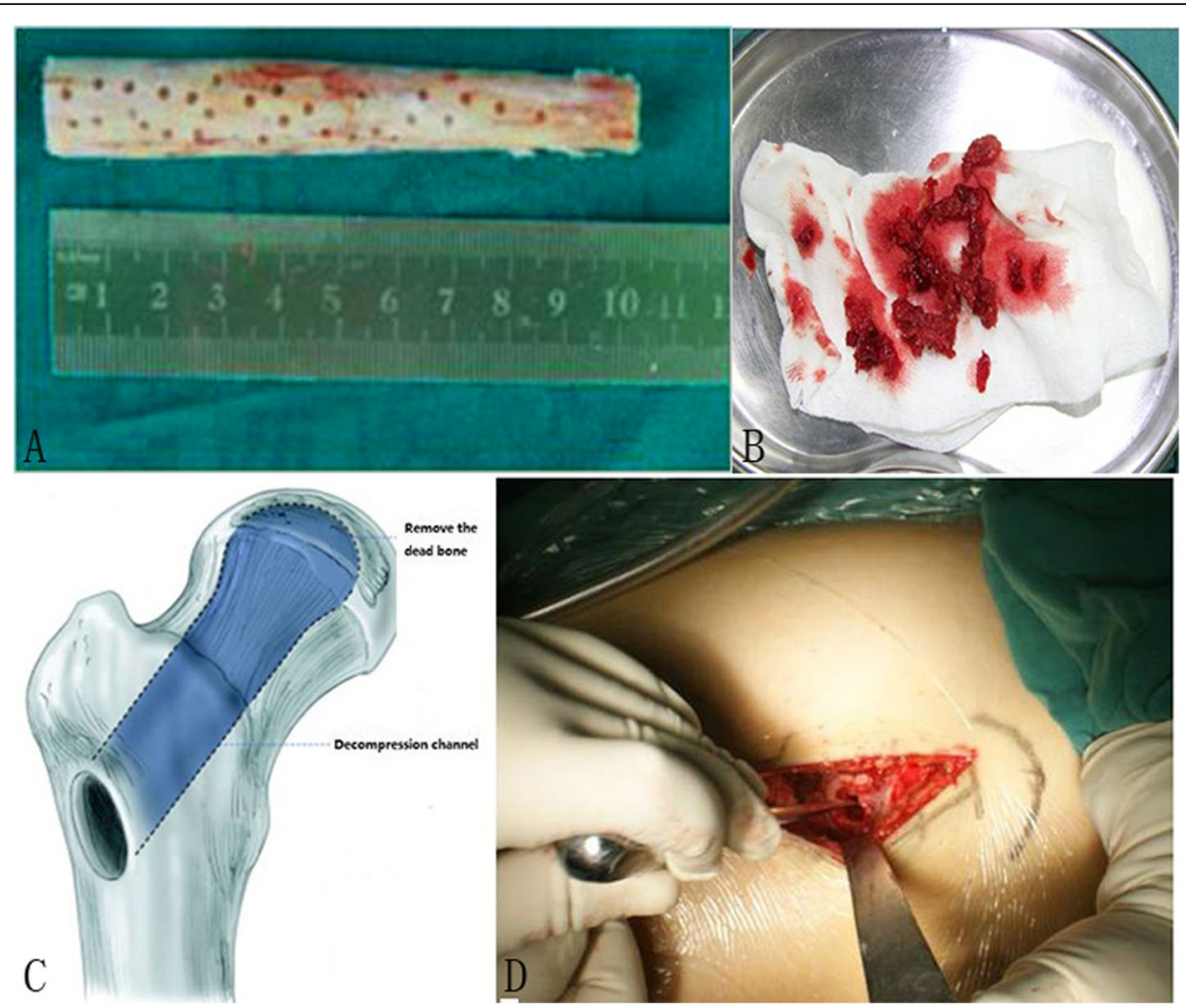

Fig. 1 a The nonvascularized allogeneic fibula with $10 \mathrm{~cm}$ long and small holes on the surface. $\mathbf{b}$ Removed the dead bone through the decompression channel. c, d Diagrammatic drawing of the decompression channel. c Creating the decompression channel during the operation. d The channel has been built and an allogeneic fibula has been grafted

month and full weight-bearing was permitted until radiographic evidence of graft healing. Strenuous activity should be avoided for a year.

\section{Outcome assessment}

Follow-up examinations included clinical and radiological assessment were scheduled at 1,4 , and 12 months and then once a year. Visual analog scale (VAS) pain scores (VAS 0; no pain to 10; extreme pain), range of hip motion (ROM) and Harris hip score (HHS, the full score is 100 marks, 90100 is excellent, $80-90$ is good, $70-80$ is ok and less than 70 is bad) was used to analyze the clinic outcome; Western Ontario McMaster Osteoarthritis index (WOMAC, including pain, stiffness, and physical function) scores and Short Form 36 health survey (SF-36) were conducted to measure the living quality; radiological assessment X-ray or computerized tomography $(\mathrm{CT})$ scan help to evaluate the stage of the disease. MRI was not routinely used for the postoperative evaluation. The survivorship was equal to the total percentage of the patients who remained in good condition and did not need to undergo the THA or fusion.

\section{Statistical analysis}

The SPSS 20.0 software was used for statistical analysis. The results were analyzed by the Student's $t$ test. A probability of less than 0.05 was considered statistically significant.

\section{Results}

Patients were followed with the examination in our outpatient service. The postoperative follow-up of these 44 patients ranged from 6 to 8.2 years with an average of 7.4 years. The mean age of the patients at the time of surgery was 36.46 years (range, $26-47$ years). There were 29 men and 15 women. Associated etiology factors included alcohol (26 patients), steroid use (15 patients), and idiopathic (3 patients). The radiographic appearance, according to the Ficat classification for ONFH,44 patients were at FicatII stage at the time of surgery. During the follow-up, 6 patients were lost for different reasons and 44 patients were included in this study. No serious complications, such as deep infection, fracture, and grafted bone dislocation, have happened.

\section{Clinical and health assessment}

The majority of patients reported considerable relief of hip pain at night and better hip motion in daily activity and work. VAS scores at rest or activity were improved from 2.3 to 1.2 on average or from 4.0 to 2.8 on average, respectively. And the overall HHS scores were improved 
from 70.5 to 82.5 on average at the last follow-up, and 10 cases showed an excellent outcome, 18 patients were with good results, 11 cases had ok scores but 5 were bad. All of the range of motion (ROM) items at last follow-up, including flexion, abduction, adduction, external rotation, internal rotation, achieved significant improvement compared with pre-operation. The mean VAS score, ROM, and Harris hip score were significantly improved at final follow-up compared with preoperative values $(p<0.001)$, and health assessment items including WOMAC scores and SF-36 were also better than preoperation $(p<0.001)$, details were shown in Table 2 .

\section{Radiographic outcomes}

At the last follow-up, the radiographic outcome was improved in 5 patients with the classification of Ficat I and 28 patients remained unchanged. However, 11 patients had a radiographic progression, in which 7 patients progressed to Ficat III with the femoral head collapsed and the rest 4 progressed to Ficat IV with mild osteoarthritis.

Table 2 baseline and outcomes of the last fellow-up

\begin{tabular}{|c|c|c|c|}
\hline Variable & Pre-operation & Last follow-up & $p$ values \\
\hline \multicolumn{4}{|l|}{ Clinical outcomes } \\
\hline \multicolumn{4}{|l|}{ VAS score } \\
\hline At rest & $2.3(1.5-2.8)$ & $1.2(0-3.4)$ & $p<0.001$ \\
\hline With activity & $4.0(3.1-4.6)$ & 2.8(1.9-4.8) & $p<0.001$ \\
\hline Hip Harris score & $70.5(66-74)$ & $82.5(52-92)$ & $p<0.001$ \\
\hline \multicolumn{4}{|l|}{$\operatorname{ROM}\left({ }^{\circ}\right)$} \\
\hline Flexion & $90.8(86.4-96.8)$ & $104.5(76.3-115.7)$ & $p<0.001$ \\
\hline Abduction & $31.1(27.6-35.2)$ & $38.5(22.0-43.8)$ & $p<0.001$ \\
\hline Adduction & $16.6(15.9-17.4)$ & $22.3(16.0-24.3)$ & $p<0.001$ \\
\hline External rotation & $30.2(28.8-31.6)$ & $39.1(21.8-43.6)$ & $p<0.001$ \\
\hline Internal rotation & $11.2(10.1-12.7)$ & $18.9(9.5-22.2)$ & $p<0.001$ \\
\hline \multicolumn{4}{|l|}{ Health status } \\
\hline \multicolumn{4}{|l|}{ WOMAC } \\
\hline Pain (0-20) & $9.4(5-11)$ & $4.4(2-12)$ & $p<0.001$ \\
\hline Stiffness (0-8) & $3.1(0-4)$ & $2.2(0-3)$ & $p=0.002$ \\
\hline Function (0-68) & $44.6(32-58)$ & $28.3(19-60)$ & $p<0.001$ \\
\hline \multicolumn{4}{|l|}{ SF-36 ${ }^{b}$} \\
\hline General health & $56.4(47.0-66.0)$ & $62.5(45.0-74.0)$ & $p<0.001$ \\
\hline Mental health & $70.6(65.0-74.0)$ & $71.2(58.0-80.0)$ & $p=0.122$ \\
\hline Bodily pain & $67.2(60.0-73.0)$ & $82.4(60.0-90.0)$ & $p<0.001$ \\
\hline Physical function & $59.9(46.0-65.0)$ & $74.8(48.0-86.0)$ & $p<0.001$ \\
\hline Social function & $65.4(55.0-72.0)$ & $76.9(53.0-84.0)$ & $p<0.001$ \\
\hline
\end{tabular}

${ }^{a}$ WOMAC dimension scores range 0-20 (pain), 0-8 (stiffness) and 0-68 (physical function); a higher score indicates increased pain or stiffness or worse physical function

bSF-36 dimension scores range 0-100: a higher score for each dimension indicates the better health-related quality of life
The 7.4-year radiographic progression rate was $25 \%$. The representative case is shown in Figs. 2 and 3.

\section{Survivorship}

There are 11 patients progressed and had the femoral head collapsed during follow-up time, 4 of whom had a good condition and the pain can be controlled after taking a small amount of painkiller without the gastrointestinal function being harmed. However, 8 patients who cannot tolerate the pain and had poor living quality underwent THA. The success rate of 7 years was $81.8 \%$.

\section{Discussion}

In this study, we evaluated the clinical results, health status, radiographic outcomes, and survivorship at a midand long-term follow-up after treating the early ONFH with modified non-vascularized allogeneic fibula grafting combined with core decompression and bone grafting. According to our outcomes, the clinical results evaluated with VAS score, HHS, the ROM, and health status assessed with WOMAC scores and SF-36 were improved significantly; 11 cases had radiographic progression with a rate of 25\%; 8 patients had THA and the 7 years' success rate was $81.8 \%$.

In order to protect the femoral head from collapse and delay the THA, it is important to take effective and positive measures to protect the femoral head at the early stages of ONFH. Two key points must be considered. The first one, the biological factor, which included removing the dead bone adequately and promote bone regeneration and blood flow recovery. The other is biomechanics factor that is to implant the scaffold, including implantation bioactive materials or not, to function as mechanical supporting and osteoconduction to the defect area so that it can delay or prevent the femoral head from collapse $[18,19]$. Though several studies have revealed that tantalum rod insertion can effectively delay or prevent the progression of osteonecrosis of the femoral head, whose overall survival rates were 68.1 to $72.49 \%$ at 48 to 60 months postoperatively [20, 21]. However, in our institution, we found a limited curative effect of tantalum rod implantation. In contrast with the disadvantages of transtrochanteric rotational osteotomy and tantalum rod placement, vascularized fibular graft with greater nutrient blood supply was preserved, osteocytes and osteoblasts remained, significantly enhance the biological and mechanical properties to the necrosis area, which exerting excellent effects in improving the clinical outcomes and survivorship [22-25]. As shown in Table 3, the middle follow-up outcomes were various with a success rate of 60 to $100 \%$, which was encouraging. But complications often occur after the surgery, especially when the fibula is harvested, which may decrease the satisfactory degree of the patients. Free 


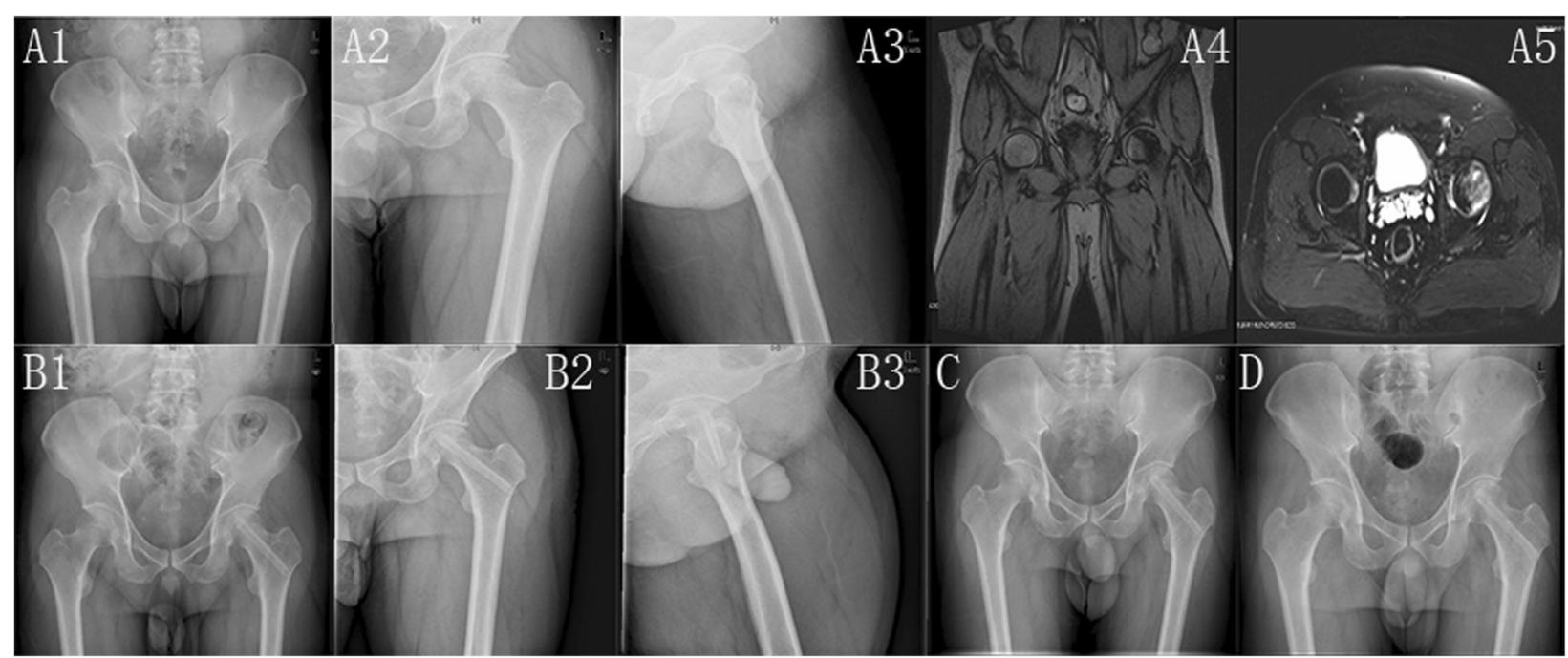

Fig. 2 The radiographic outcomes of a 36-year-old man with a long history of drinking and was diagnosed as left femoral head necrosis at Ficat II stage. A1-A5 The patient has early femoral head necrosis evaluated by X film and MRI respectively. B1-B3 The X film of 3 days after the operation. It shows that the femoral head is in normal shape and the grafted fibula integrates tightly in the channel. C, D The images at 1 and 4 months after the operation, respectively. E1-E3 The images at 2 years after the operation. F1-F3 The images at 5 years after the operation, which shows the stability of the articular cartilage and femoral head. G1-G3 The images at 8.2 years after the operation. The femoral head is not progressed and keeps in good shape. The left femoral head was in Ficat I stage and the Harris score was 90 at the last follow-up

vascularized fibular grafting used for ONFH has been associated with proximal femoral fracture and donor-site morbidity including sensory abnormalities, motor weakness, and ankle pain, which might influence the recovery of the patients and prolong the rehabilitation [14]. In order to obtain the free vascularized bone, a $10 \mathrm{~cm}$ to $15 \mathrm{~cm}$ fibular is removed from the patients, leaving remnants of bone proximally and distally, which may increase the instability of the lower extremity, though mostly acceptable but should also take into account [30]. According to the previous studies, about one-fourth of the patients reported discomfort, pain or swelling, and sensory deficits in $76.3 \%$, motor deficits in $39.5 \%$ and reduced strength in $44.7 \%$ were found in the included patients at the time of follow-up examination [31]. Moreover, free vascularized fibula graft surgery is complicated, thus, most of the community hospitals or less prosperous region think it is impractical to do such a surgery so that they continue to perform core decompression today [32]. Consequently, although the free vascularized fibular grafting has good effects on treating ONFH, potential complications and the cost-effective value are needed to be taken into consideration and more appropriate techniques should still be researched.

Currently, many studies have compared the safety and efficiency of vascularized and non-vascularized fibular grafting, most of which found that vascularized fibular grafting treatment have a better survival rate as well as better clinical and radiological results than non-vascularized fibular grafting treatment $[25,33]$. However, different from the precious non-vascularized fibular grafting method, our modified one shows a satisfactory survival rate as well as clinical and radiological outcomes and decreases complexity and the occurrence of adverse events. In our study, we chose the non-vascularized polyporous allogeneic fibula from the bone bank of our hospital as the graft material. In order to increase the bioactivity, we grafted autogenic cancellous bone to the femoral head before the transplantation. According to our outcomes, our surgery significantly reduced the pain, increased the range of the motion and improved the HHS, which demonstrated that modified non-vascularized allogeneic fibula grafting combined with core decompression and bone grafting had effects on improving the clinical results. And then, at our mean 7.4 years follow-up, most of the patients were not progressed when evaluated by the radiographic examination and some of them even improved to the better classification. This helps to prove that our modified operation contributed to protecting the femoral head from becoming worse. Furthermore, the success rate of this study came to $81.8 \%$ and was not inferior to free vascularized fibular grafting based on the above studies. Moreover, there were no obvious complications that happened during our follow-up, and the patients achieved a faster rehabilitation and better living quality after operation for not removing the autogenous fibula that could prolong the operation time and hospital stays, increase the blood loss and local pain or dysaesthesia. When evaluating the health status, WOMAC and SF-36 showed improved outcomes in the living quality items, which include pain, stiffness, physical function, and social 


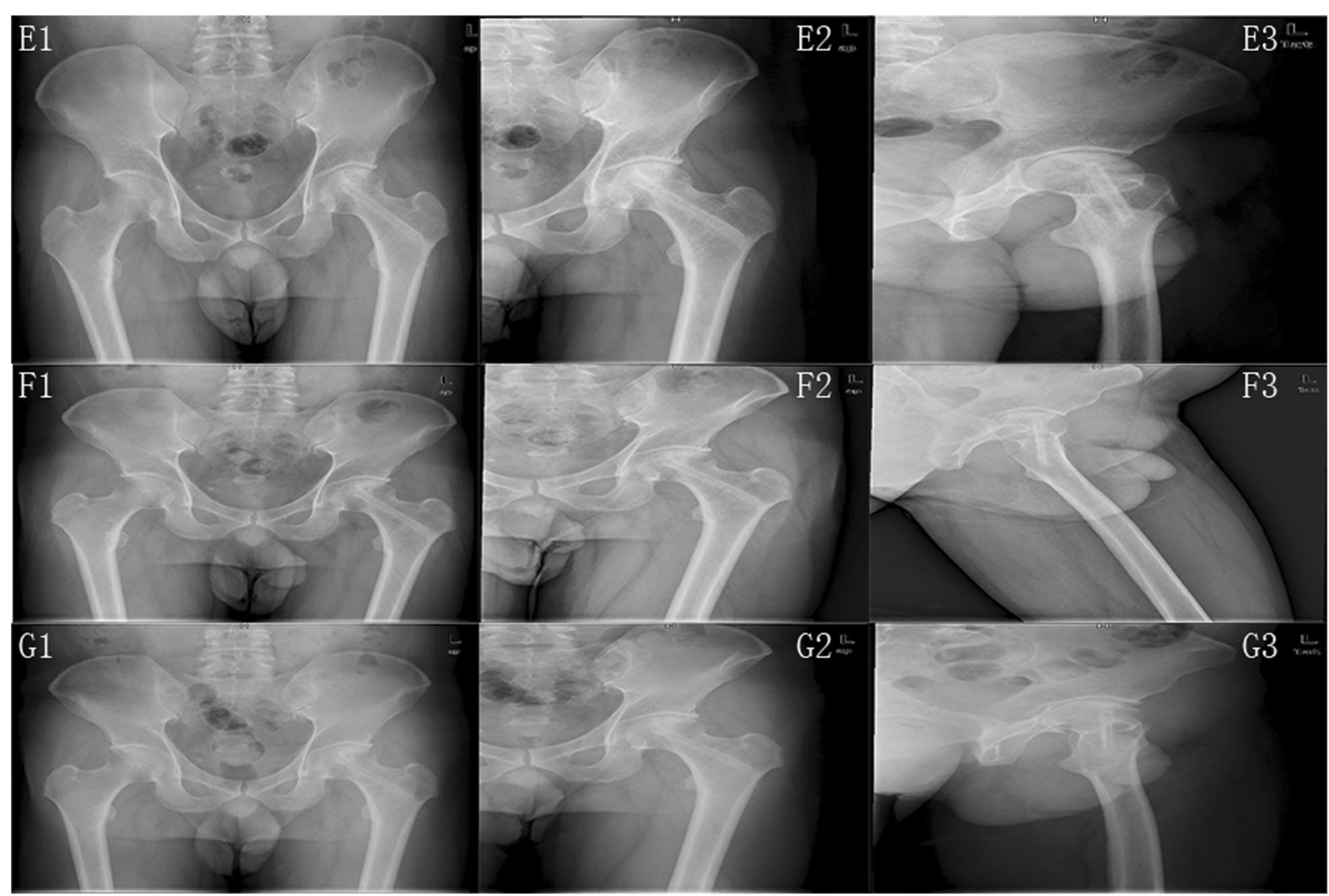

Fig. 3 The radiographic outcomes of a 36 years old man with a long history of drinking and was diagnosed as left femoral head necrosis at Ficat II stage. A1-A5 The patient has early femoral head necrosis evaluated by X film and MRI respectively. B1-B3 The X film of 3 days after the operation. It shows that the femoral head is in normal shape and the grafted fibula integrates tightly in the channel. C, D The images at 1 and 4 months after operation respectively. E1-E3 The images at 2 years after the operation. F1-F3 The images at 5 years after the operation, which shows the stability of the articular cartilage and femoral head. G1-G3 The images at 8.2 years after the operation. The femoral head is not progressed and keeps in good shape. The left femoral head was in Ficat I stage and the Harris score was 90 at the last follow-up

Table 3 Results of fibular grafting for the treatment of ONFH according to the literature

\begin{tabular}{llllcc}
\hline Reference & Year of publication & Number of hips & Treatment measures & Follow-up in months & $\begin{array}{c}\text { Success } \\
\text { rate (\%) }\end{array}$ \\
\hline Sotereanos [26] & 1997 & 88 & Free vascularized fibula graft & 66 months & 77.3 \\
Berend [15] & 2003 & 224 & Free vascularized fibular grafting & 60 months & 64.5 \\
Bertrand [16] & 2013 & 52 & Vascularized fibular graft & 19 months & 90.1 \\
Gao [17] & 2013 & 42 & Free vascularized fibula graft & 42 months & 100 \\
Buckley [27] & 1991 & 20 & Tibial or fibular autogenous graft, & 24 months & 95 \\
Yin [22] & 2011 & 14 & Free vascularized fibular grafting & 18 months & 36 months \\
Lin [28] & 2009 & 32 & Allograft fibula grafting & 93.8 \\
Eward [23] & 2012 & 65 & Vascularized fibular graft, free vascularized fibular graft & 96 months \\
Zhang [29] & 2011 & 28 & Vascularized fibular grafting & 48 months & 60 \\
Kim [24] & 2005 & 23 & Non-vascularized fibular grafting & 48 months & 86 \\
& & 23 & Vascularized fibular grafting & 48 months & 78 \\
Plakseychuk [25] & 2003 & 220 & Non-vascularized fibular grafting & 84 months \\
& & 123 & & 84 months & 30 \\
\hline
\end{tabular}


function. Besides, Zeng Y et al. [34] found that core decompression followed by bone grafting combining with nonvascularized fibular allografting in one hip and concurrent one-stage total hip arthroplasty (THA) in the contralateral side is efficient for the treatment of bilateral osteonecrosis of the femoral head in the short term, which can provide biological stability and sufficient blood supply and obtain longtime repairmen of the necrotic bone. Combined with previous studies and our outcomes, we may prove that patients with ONFH have good tolerance to this modified surgery in the mid- to long-term, and can obtain a quick physical function recovery and high satisfaction of living.

Normally, a combination of allogeneic and autologous bone transplants is a reliable method to biologically reconstruct bone defects, of which autologous cancellous bone is well-known for its osteogenic potential; and combined therapy can provide desirable safe load transmission and osteoinduction and remodeling $[35,36]$. In the present study, allogeneic-fibular from the bone bank remains the same structures as an autogenous bone with antigen removal could be an effective supporting material to the subchondral architecture. At the same time, the autogenic cancellous bone can function as a good structure, which might facilitate mesenchymal stem cells associated with bone regeneration, adding the osteogenic activity to the necrosis area and benefiting the repair of the defects [37]. However, several limitations were obvious in our study. First, we only included 44 hips in our research and our outcomes may not persuasive enough yet. Second, the allogeneic-fibular is very limited in clinical, so it is necessary and important to build a bone bank. Third, our follow-up period is still not long enough and longer-terms of follow-up are still needed to prove our results. Fourth, we failed to include advanced stages of ONFH, it is imperative to estimate the curative effect of our method in these patients.

In conclusion, modified non-vascularized allogeneic fibula grafting combined with core decompression and bone grafting exerted is an effective and cost-effective treatment on early femoral head necrosis with satisfactory survivorship and could improve the clinical outcomes, delay the disease progression, and enhance the quality of life for patients.

\footnotetext{
Abbreviations

HHS: Harris hip score; ONFH: Osteonecrosis of femoral head; ROM: Range of hip motion; SF-36: Short Form 36 health survey; THA: Total hip arthroplasty; VAS: Visual analog scale; WOMAC: Western Ontario McMaster Osteoarthritis index
}

\section{Acknowledgements}

We want to express our sincere appreciation for all the patients that joined this study.

\section{Authors' contributions}

CCJ was responsible for data analysis and manuscript writing. LDH contributed to data collection and language editing. ZX, CLYL, and WQR contributed to the data collection. KPD was responsible for the study design and correspondence. All authors read and approved the final manuscript.

\section{Funding}

This work was supported by the National Natural Science Foundation of China (grant numbers 81672165 and 81401528); the Technology R\&D Program of Sichuan Province, China (grant number 2019YFS0123). 1.3.5 project for disciplines of excellence, West China Hospital, Sichuan University.

\section{Availability of data and materials}

The datasets used and/or analyzed during the current study are available from the corresponding author on reasonable request.

\section{Ethics approval and consent to participate}

The study was approved by the Clinical Trials and Biomedical Ethics Committee of West China Hospital (NO.201407146), and written informed consent was obtained from all participants. All experiments were performed in accordance with relevant guidelines and regulations.

\section{Consent for publication}

All authors have seen the manuscript and approved it to submit to your journal.

\section{Competing interests}

The authors declare that they have no competing interests.

Received: 3 December 2019 Accepted: 16 January 2020

Published online: 24 March 2020

\section{References}

1. Seamon J, Keller T, Saleh J, Cui Q. The pathogenesis of nontraumatic osteonecrosis. Arthritis. 2012;2012:601763.

2. Xu S, Zhang $L$, Jin $H$, Shan $L$, Zhou $L$, Xiao $L$, et al. Autologous stem cells combined Core decompression for treatment of avascular necrosis of the femoral head: a systematic meta-analysis. Biomed Res Int. 2017;2017: 6136205.

3. Kang P, Pei F, Shen B, Zhou Z, Yang J. Are the results of multiple drilling and alendronate for osteonecrosis of the femoral head better than those of multiple drilling? A pilot study. Joint Bone Spine. 2012;79(1):67-72.

4. Asano T, Takahashi D, Shimizu T, Irie T, Arai R, Terkawi MA, et al. A mathematical model for predicting postoperative leg shortening after curved intertrochanteric varus osteotomy for osteonecrosis of the femoral head. PLoS One. 2018;13(12):e0208818.

5. Wang CJ, Wang FS, Huang CC, Yang KD, Weng LH, Huang HY. Treatment for osteonecrosis of the femoral head: comparison of extracorporeal shock waves with core decompression and bone-grafting. J Bone Joint Surg Am. 2005;87(11):2380-7.

6. Liu Y, Yan L, Zhou S, Su X, Cao Y, Wang C, et al. Tantalum rod implantation for femoral head osteonecrosis: survivorship analysis and determination of prognostic factors for total hip arthroplasty. Int Orthop. 2016;40(7):1397-407.

7. Xie H, Wang B, Tian S, Liu B, Qin K, Zhao D. Retrospective long-term followup survival analysis of the Management of Osteonecrosis of the femoral head with Pedicled vascularized iliac bone graft transfer. J Arthroplasty. 2019;34(8):1585-92.

8. Hong YC, Zhong HM, Lin T, Shi JB. Comparison of core decompression and conservative treatment for avascular necrosis of femoral head at early stage: a meta-analysis. Int J Clin Exp Med. 2015;8(4):5207-16.

9. Cao L, Guo C, Chen J, Chen Z, Yan Z. Free vascularized fibular grafting improves vascularity compared with Core decompression in femoral head osteonecrosis: a randomized clinical trial. Clin Orthop Relat Res. 2017;475(9): 2230-40.

10. Rijnen WH, Gardeniers JW, Westrek BL, Buma P, Schreurs BW. Sugioka's osteotomy for femoral-head necrosis in young Caucasians. Int Orthop. 2005; 29(3):140-4

11. Dean MT, Cabanela ME. Transtrochanteric anterior rotational osteotomy for avascular necrosis of the femoral head. Long-term results. J Bone Joint Surg. 1993;75(4):597-601.

12. Shuler MS, Rooks MD, Roberson JR. Porous tantalum implant in early osteonecrosis of the hip: preliminary report on operative, survival, and outcomes results. J Arthroplasty. 2007;22(1):26-31. 
13. Tanzer M, Bobyn JD, Krygier JJ, Karabasz D. Histopathologic retrieval analysis of clinically failed porous tantalum osteonecrosis implants. J Bone Joint Surg Am. 2008;90(6):1282-9.

14. Gaskill TR, Urbaniak JR, Aldridge JM 3rd. Free vascularized fibular transfer for femoral head osteonecrosis: donor and graft site morbidity. J Bone Joint Surg Am. 2009;91(8):1861-7.

15. Berend KR, Gunneson EE, Urbaniak JR. Free vascularized fibular grafting for the treatment of postcollapse osteonecrosis of the femoral head. J Bone Joint Surg Am. 2003;85(6):987-93.

16. Bertrand T, Urbaniak JR, Lark RK. Vascularized fibular grafts for avascular necrosis after slipped capital femoral epiphysis: is hip preservation possible? Clin Orthop Relat Res. 2013;471(7):2206-11.

17. Gao YS, Liu XL, Sheng JG, Zhang CQ, Jin DX, Mei GH. Unilateral free vascularized fibula shared for the treatment of bilateral osteonecrosis of the femoral head. J Arthroplasty. 2013;28(3):531-6.

18. Hernigou P, Flouzat-Lachaniette $\mathrm{CH}$, Delambre J, Poignard A, Allain J, Chevallier $\mathrm{N}$, et al. Osteonecrosis repair with bone marrow cell therapies: state of the clinical art. Bone. 2015;70:102-9.

19. Kang P, Shen B, Yang J, Cheng J, Pei F. Repairing defect and preventing collapse of canine femoral head using titanium implant enhanced by autogenous bone graft and rhBMP-2. Connect Tissue Res. 2007;48(4):171-9.

20. Veillette CJ, Mehdian H, Schemitsch EH, McKee MD. Survivorship analysis and radiographic outcome following tantalum rod insertion for osteonecrosis of the femoral head. J Bone Joint Surg Am. 2006;88(Suppl 3):48-55.

21. Liu Y, Su X, Zhou S, Wang L, Wang C, Liu S. A modified porous tantalum implant technique for osteonecrosis of the femoral head: survivorship analysis and prognostic factors for radiographic progression and conversion to total hip arthroplasty. Int J Clin Exp Med. 2015;8(2):1918-30.

22. Yin S, Zhang C, Jin D, Chen S, Sun Y, Sheng J. Treatment of osteonecrosis of the femoral head in lymphoma patients by free vascularised fibular grafting. Int Orthop. 2011;35(8):1125-30.

23. Eward WC, Rineer CA, Urbaniak JR, Richard MJ, Ruch DS. The vascularized fibular graft in precollapse osteonecrosis: is long-term hip preservation possible? Clin Orthop Relat Res. 2012;470(10):2819-26.

24. Kim SY, Kim YG, Kim PT, Ihn JC, Cho BC, Koo KH. Vascularized compared with nonvascularized fibular grafts for large osteonecrotic lesions of the femoral head. J Bone Joint Surg Am. 2005;87(9):2012-8.

25. Plakseychuk AY, Kim SY, Park BC, Varitimidis SE, Rubash HE, Sotereanos DG. Vascularized compared with nonvascularized fibular grafting for the treatment of osteonecrosis of the femoral head. J Bone Joint Surg Am. 2003:85(4):589-96

26. Sotereanos DG, Plakseychuk AY, Rubash HE. Free vascularized fibula grafting for the treatment of osteonecrosis of the femoral head. Clinical Orthopaedics and Related Research. 1997;(344):243-56.

27. Buckley PD, Gearen PF, Petty RW. Structural bone-grafting for early atraumatic avascular necrosis of the femoral head. The Journal of Bone and Joint surgery. American Volume. 1991;73(9):1357-64.

28. Lin ZJ, Su PJ, Wu ZQ, et al. [Pith decompression of the femoral head and allograft fibula grafting for treatment of avascular necrosis of femoral head]. Zhongguo gu Shang = China Journal of Orthopaedics and Traumatology. 2009;22(8):628-30.

29. Zhang CQ, Sun Y, Chen SB, et al. Free vascularised fibular graft for posttraumatic osteonecrosis of the femoral head in teenage patients. The Journal of Bone and Joint surgery. British Volume. 2011;93(10):1314-19. https://doi.org/10.1302/0301-620x.93b10.26555.

30. Garrett A, Ducic Y, Athre RS, Motley T, Carpenter B. Evaluation of fibula free flap donor site morbidity. Am J Otolaryngol. 2006;27(1):29-32.

31. Zimmermann CE, Borner Bl, Hasse A, Sieg P. Donor site morbidity after microvascular fibula transfer. Clin Oral Investig. 2001;5(4):214-9.

32. Plakseychuk A. CORR insights((R)): free vascularized fibular grafting improves vascularity compared with Core decompression in femoral head osteonecrosis: a randomized clinical trial. Clin Orthop Relat Res. 2017;475(9):2241-4.

33. Tetik C, Basar H, Bezer M, Erol B, Agir I, Esemenli T. Comparison of early results of vascularized and non-vascularized fibular grafting in the treatment of osteonecrosis of the femoral head. Acta Orthop Traumatol Turc. 2011; 45(5):326-34.

34. Zeng Y, Qi X, Feng W, Li J, Li F, Zeng J, et al. One-sided hip-preserving and concurrent contralateral total hip arthroplasty for the treatment of bilateral osteonecrosis of the femoral head in different stages: short-medium term outcomes. BMC Musculoskelet Disord. 2015;16:133.
35. Windhager R, Hobusch GM, Matzner M. Allogeneic transplants for biological reconstruction of bone defects. Der Orthopade. 2017;46(8):656-64.

36. Basarir K, Selek H, Yildiz Y, Saglik Y. Nonvascularized fibular grafts in the reconstruction of bone defects in orthopedic oncology. Acta Orthop Traumatol Turc. 2005;39(4):300-6.

37. Joo MW, Chung SJ, Shin SH, Chung YG. The effect of autologous plateletrich plasma on bone regeneration by autologous Mesenchymal stem cells loaded onto allogeneic Cancellous bone granules. Cells Tissues Organs. 2017;203(6):327-38.

\section{Publisher's Note}

Springer Nature remains neutral with regard to jurisdictional claims in published maps and institutional affiliations.
Ready to submit your research? Choose BMC and benefit from:

- fast, convenient online submission

- thorough peer review by experienced researchers in your field

- rapid publication on acceptance

- support for research data, including large and complex data types

- gold Open Access which fosters wider collaboration and increased citations

- maximum visibility for your research: over $100 \mathrm{M}$ website views per year

At BMC, research is always in progress.

Learn more biomedcentral.com/submissions 